\title{
Kai Ambos, Derecho Penal Internacional Económico. Fundamentos de la responsabilidad penal internacional de las empresas
}

(2018) Editorial Civitas

Madrid, $167 \mathrm{pp}$.

\author{
Daniel González Uriel ${ }^{*}$ \\ Universidad de Santiago de Compostela \\ ORCID ID 0000-0001-8966-0571 \\ daniel.gonzalez@poderjudicial.es
}
Cita recomendada:
González Uriel, D. (2019). Kai Ambos, Derecho Penal Internacional Económico. Fundamentos de la responsabilidad penal internacional de las empresas. Eunomía. Revista en Cultura de la Legalidad, 17, 408-413.
doi: https://doi.org/10.20318/eunomia.2019.5046

La monografía recensionada pertenece a la colección Cuadernos Civitas y presenta un formato reducido. Se estructura en cinco capítulos breves y unas conclusiones, que se distribuyen en 167 páginas. En su composición destacan, por su relevancia cualitativa y dogmática, los capítulos IV y V.

Kai Ambos es catedrático de Derecho Penal, Procesal Penal, Derecho Comparado y Derecho Penal Internacional en la Facultad de Derecho de la GeorgAugust-Universität Götingen de Alemania, Director del General del Centro de Estudios de Derecho Penal y Procesal Latinoamericano de dicha (CEDPAL) de dicha Universidad, ha sido Juez del Tribunal Especial de la Haya para Kosovo y amicus curiae de la Jurisdicción Especial para la Paz (JEP) en Colombia.

En esta obra teoriza sobre la posibilidad de construir un sistema dogmático de responsabilidad penal internacional de las organizaciones empresariales, efectuando

\footnotetext{
* Juez. Doctorando en la Universidad de Santiago de Compostela.
} 
una contextualización histórica de sus precedentes inmediatos. En sus seis capítulos se analizan los siguientes aspectos: el Capítulo (Cap.) I efectúa unas observaciones conceptuales preliminares. En el Cap. II se aborda la intervención de las empresas en el injusto penal internacional. El Cap. III se centra en el análisis de la praxis del Derecho Penal Internacional (DPI). El Cap. IV estudia las cuestiones relativas a la responsabilidad jurídica. Por su parte, el Cap. V profundiza en las formas de intervención punible. En último término, en el Cap. VI se apuntan una serie de conclusiones.

Por lo que hace al introductorio Cap. I, efectúa unas delimitaciones conceptuales. En él se define al Derecho Penal Internacional Económico (DPIE) como una parte del DPI que se ocupa de los comportamientos de las empresas o de sus responsables que conllevan infracción de normas penales del Derecho Internacional. El fin de protección de dicha disciplina es distinto del amparado por el Derecho Penal Económico, por cuanto en este ámbito se protegen los mismos bienes jurídicos que en el DPI en general: la paz, la seguridad y los Derechos Humanos.

En el breve Cap. II, Ambos sintetiza la intervención de las empresas en el injusto penal internacional, que puede realizarse en calidad de autoría directa e indirecta. La autoría directa es menos frecuente, y en ella la empresa o sus trabajadores cometen el hecho, v. gr., el saqueo o el sometimiento a esclavitud. En segundo lugar, la complicidad, que clasifica en tres tipos: i) directa, cuando la empresa provee bienes o servicios que serán usados en la violación de Derechos Humanos; ii) indirecta, cuando dicha entidad se beneficia de tal violación, incluso sin haber cooperado a la misma y iii) silenciosa: la empresa no hace nada para evitar la violación (lo que se ubicaría en la dimensión moral de su conducta).

Por su parte, el Cap. III realiza un repaso histórico sobre la praxis del DPI, comenzando por Núremberg, en que se sucedieron una serie de procesos subsecuentes contra empresarios y banqueros, en los que las personas naturales comparecieron debido a su intervención en los crímenes alemanes y japoneses. Se sostiene que la responsabilidad colectiva de las empresas alemanas líderes constituía el mensaje de los procesos contra sus representantes. En uno de los juicios más sonados, el seguido contra la empresa Farben, se reconoció explícitamente la peligrosidad de la intervención empresarial en los crímenes internacionales. Dicha relevancia va aparejada al "incremento del riesgo generado por estructuras empresariales configuradas de modo cómplice". De esta praxis se extrae la obligación de las empresas de abstenerse de cometer actos que constituyan crímenes internacionales.

En lo tocante a la situación actual, a nivel supranacional no existe ningún tribunal penal internacional que pueda condenar a una empresa como tal, ya que los tratados solo obligan a los Estados. Sin embargo, desde la aprobación de los Principios Rectores sobre Empresas y Derechos Humanos, de la Organización de las Naciones Unidas (ONU), surge una tendencia al reconocimiento de obligaciones de Derechos Humanos en el ámbito del soft law, si bien, la responsabilidad empresarial se fija en ellos de modo moral. Ha de subrayarse que la Corte Penal Internacional (CPI) solo tiene competencia respecto de personas naturales. Sin embargo, se aprecian algunas innovaciones en la materia: en dos resoluciones del Tribunal Especial para el Líbano se acusó a dos empresas como tales -al lado de una persona natural- por infracciones contra la Administración de Justicia. Asimismo, la nueva Corte Africana de Justicia y de Derechos Humanos y de los Pueblos dispone que podría ejercer jurisdicción respecto de personas jurídicas (salvo Estados), pero aún no ha sido ratificada por el número de Estados necesarios. Otro elemento a tener en cuenta son los Tratados Internacionales que tipifican delitos en los que se exige una 
sanción a las personas jurídicas, si bien se deja libertad a los Estados Parte, por lo que la respuesta puede ser no penal. Estima el autor que dicha praxis se basa en que las normas de comportamiento (primarias) que subyacen a las normas de sanción (secundarias) del DPI -a pesar de la ausencia de jurisdicción- también resultan vinculantes para los colectivos. Así, combina el deber derivado de dicho ordenamiento internacional con la vinculatoriedad en surgimiento de los Derechos Humanos, y fundamenta en ello la vinculación jurídica (y no solo moral) de las empresas. En el ámbito nacional, pone varios ejemplos de dicha práctica: los colaboradores que vendieron insumos de gas mostaza a Sadam Husein -con los que gaseó a la población del Kurdistán iraquí-, o aquéllos que financiaron el conflicto en Liberia. En ambos supuestos, las agencias de persecución se sirvieron de personas naturales para acceder a las personas jurídicas subyacentes, y reconocieron con ello, en todo caso de forma mediata, la responsabilidad de éstas.

El Cap. IV aborda distintas cuestiones sobre responsabilidad penal de las personas jurídicas. Como cuestión previa apunta los aspectos favorables a su incriminación penal: i) el surgimiento de la estructura empresarial favorece o promueve la comisión de delitos, ii) la mayor estigmatización del proceso penal, iii) la asunción de intimidación más efectiva frente a agentes racionales y iv) una esperanza de recuperación de activos más sencilla. Sin embargo, refiere que parece contradictorio aducir a favor de dicho modelo de atribución de responsabilidad los fines y funciones del Derecho Penal tradicional. No obstante, sostiene que la empresa es algo más que la suma de sus miembros, por lo que se trata de un injusto merecedor de pena, y la entidad se constituye en un destinatario merecedor de la imputación. A su vez, diferencia dos modelos de atribución del reproche: el de organización y el de atribución. Ambos toma como punto de partida la fragmentación de enfoques existente en los Derechos nacionales. En el sistema de organización surge la culpabilidad por organización de la empresa. Se entiende que siempre actúan por medio de personas naturales, pero se acude, dentro de sus partidarios más extremos, a un "concepto constructivista de la culpabilidad empresarial", y se pone el acento en el grado de autoorganización y de autonomización. La culpabilidad por organización puede presumirse cuando la empresa no instaura un programa de compliance, en especial, respecto a riesgos para los Derechos Humanos.

En el modelo de atribución la responsabilidad se vincula, de modo derivado, al comportamiento del miembro de la empresa, por lo que surge una duplicación o acumulación de la responsabilidad. En su seno se debate si es suficiente con que el hecho sea cometido por cualquier trabajador, o debe ser un directivo. En cuanto a la necesidad de identificar al trabajador, surgen problemas de comprobación relacionados con el velo corporativo. El autor manifiesta que desde la perspectiva del DPI, el sistema de atribución resulta más compatible con el Estatuto de la Corte Penal Internacional (ECPI), y defiende un sistema dual, en que se persigan los actos tanto de los directivos como de los trabajadores de la corporación.

En el Cap. V se analizan las formas de intervención punible. El artículo 25 ECPI diferencia entre autores y partícipes. La responsabilidad en concepto de autor surge en aquellos casos en que los trabajadores cometen directamente los crímenes internacionales, directamente, conjuntamente o por medio de otras personas. Sobre esta autoría mediata se presentan interrogantes en cuanto a la teoría del dominio de la organización en el caso de los trabajadores que actúan como ejecutores directos. Asimismo, en los casos de responsabilidad en coautoría aparecen dificultades para comprobar la autoría funcional. A su vez, la teoría de la "empresa criminal conjunta" conlleva problemas en la delimitación de la participación, en esencia, a propósito del "otro" aporte al crimen de un grupo. En último término, dentro del campo de la autoría, destaca la imprecisión de la responsabilidad de los directivos de la empresa a 
propósito de actos cometidos por superiores militares. Ello se agrava en el caso de las empresas transnacionales y la prueba del conocimiento o imprudencia consciente de los crímenes cometidos por sus subordinados. En cuanto a la complicidad punible ${ }^{1}$, Ambos coloca el foco de atención en su diferenciación con los actos neutrales. Parte de la dificultad de su delimitación y recoge como criterio inicial que el aporte al hecho de otro ha de ser "esencial". También subraya que es posible acudir a los criterios hermenéuticos de la teoría de la imputación objetiva. Añade otros posibles entendimientos de la complicidad como: posibilitar, exacerbar o favorecer el delito. Por el contrario, en las acciones neutrales se excluyen tendencialmente y ya en el nivel objetivo las meras operaciones comerciales. Así, ha de valorarse el incremento del riesgo o su realización en el resultado concreto, es decir, si son socialmente dañosas o concretamente peligrosas. También es relevante la valoración del contexto comisivo, v.gr., si es un Estado totalitario. Sin embargo, en la mayoría de casos el merecimiento de pena requiere una valoración global objetivo-subjetiva.

En el ámbito subjetivo de la complicidad defiende que el cómplice tiene que conocer el efecto incrementador del riesgo que tendrá su aporte, y no es preciso que sepa todos sus detalles, ya que menores exigencias subjetivas llevarían a las empresas a minuciosas investigaciones que tendrían efectos perjudiciales para las inversiones. No obstante, un requisito de intención adicional daría lugar a una restricción excesiva. Además, precisa que la intención solo ha de referirse a la acción de complicidad y no al hecho principal. Por todo ello, Ambos mantiene que ha de atenderse a un enfoque primariamente cognitivo, aunque complementado con el elemento doloso de la intención. Para cerrar el capítulo, apunta una serie de casos dudosos: la venta de armas o de vehículos, la compra de bienes de guerra (significadamente, metales preciosos como diamantes), o las empresas que colaboran en la represión con los regímenes totalitarios. En todos ellos ha de atenderse al caso concreto, así como al cumplimiento de los deberes de diligencia en el marco de las cadenas de suministro. No obstante, es compleja la verificación del tipo objetivo de la complicidad por el incremento y realización del riesgo, sobre todo en el caso de proveedores de servicios de doble uso.

La obra finaliza con una serie de conclusiones en el Cap. VI, que se pueden sintetizar en: i) si bien en Núremberg se reconoció como obvia «la relevancia de la conducta empresarial para la comisión de crímenes internacionales», ello parece haber caído en el olvido. ii) No puede sobreestimarse el DPIE, ya que tiene un dudoso efecto intimidatorio. iii) La responsabilidad penal internacional es solo una posibilidad, ya que cabe acudir a otros elementos, tales como: el compliance en Derechos Humanos o el control de la sociedad civil sobre las iniciativas de los consumidores. iv) Todos estos elementos han de integrarse en un reglamento más amplio y completo, que contemple sanciones en caso de incumplimiento. v) No obstante, no ha de cederse a las demandas apresuradas de reestructuración en el DPI. vi) En todo caso, para que sea posible la responsabilidad de la empresa, ha de poder atribuirse a la misma el comportamiento del trabajador.

Una vez que se ha esbozado el contenido de la monografía, hemos de resaltar sus aspectos positivos, entre los que se encuentran la claridad en el lenguaje, la capacidad de síntesis y la exposición de todos los elementos esenciales de una forma ordenada y completa. Pese a lo reducido de sus dimensiones, Ambos efectúa un repaso histórico-jurídico y da unas nociones sobre el desarrollo futuro de la disciplina. Entre los méritos de la obra podemos destacar que aborda un campo poco analizado hasta la fecha: la potencialidad de los poderes económicos para cometer crímenes

\footnotetext{
1 Ya tratada por el autor en un trabajo anterior: Ambos, K. (2001). La complicidad a través de acciones cotidianas o externamente neutrales. Revista de Derecho Penal y Criminología, núm. 8, pp. 195-206.
} 
que desbordan la esfera nacional y se pueden reputar como ilícitos internacionales. Es un libro que invita a la reflexión sobre la causalidad, la teoría de la imputación objetiva -representada en los criterios del incremento del riesgo y su realización en el resultado- y la participación, fundamentalmente centrada en la complicidad, en el ámbito de la delincuencia económica. Asimismo hemos de resaltar que resulta coherente, jurídicamente bien fundada y estructurada, atribuye a cada capítulo la dimensión oportuna y resulta autocrítica, por cuanto, pese a que su autor sea un partidario de la ampliación del elenco de delitos internacionales y de la introducción de la responsabilidad penal de las personas jurídicas en la esfera de delitos de la CPI, en sus conclusiones asume que no se puede sobreestimar dicha disciplina, por lo que hemos de derivar que no cumple -o lo hace de forma insuficiente- la función de prevención general. Además, resulta didáctica, combina los ámbitos doctrinal y jurisprudencial de un modo magistral y aporta soluciones útiles para interpretar los casos dudosos.

En cuanto a las matizaciones que podemos efectuar, en primer término debemos señalar que algunos aspectos son tratados de una forma excesivamente escueta, lo que se justifica en la brevedad de la obra y en que su función no es ser un manual. Como ejemplos de esta puntualización podemos mencionar la brevedad con que se trata la autoría, o que las precisiones conceptuales solo se refieran a la denominación de la disciplina y a los fines perseguidos. Sin embargo, en cuanto al fondo, podemos discrepar de una serie de postulados del autor alemán: en primer lugar, no se comparte la necesidad de ampliación de ilícitos recogidos en el ECPI, ni que la responsabilidad penal de las personas jurídicas deba ser introducida en la misma. En este sentido, podemos traer a colación que se ha defendido ${ }^{2}$ la necesidad de introducir una serie de delitos medioambientales en el ECPI. No se comparte esta línea expansiva, toda vez que tiene el inconveniente de la falta de un consenso internacional a propósito de la tipificación de tales conductas y, fundamentalmente, el defecto de postergar gran parte de la protección a un tribunal ad hoc, especial, sin tal atribución competencial en el caso de la CPI, o aún no creado -si se opta por la creación de un órgano nuevo-, con la posible vulneración del principio del juez ordinario predeterminado por la ley. Además, parte de una desconfianza innecesaria en los sistemas judiciales internos.

Un segundo aspecto que diluye las propuestas de Ambos es la ausencia de quorum a propósito de la responsabilidad penal de los entes corporativos, ya que se ha discutido prácticamente todo: su necesidad, sus bases teóricas, su sistema de imputación, la aplicación de las categorías dogmáticas del denominado «Derecho Penal Clásico» o las sanciones a aplicar. Además, deben resaltarse las grandes divergencias existentes entre los propios ordenamientos nacionales que han instaurado dicha responsabilidad. Por ello, resulta controvertido que se incluya dicha modalidad como elemento clave en el DPI.

Pese a que nos hallemos en pleno «Derecho Penal Moderno», con ${ }^{3}$ la proliferación de los delitos de peligro, la abstracción de los bienes jurídicos, la relativización de la diferencia entre la autoría y la participación, la quiebra del principio de proporcionalidad -al castigarse comportamientos imprudentes en relación con bienes jurídicos colectivos-, la expansión del Derecho Penal por la globalización y la integración supranacionales, el incremento de los riesgos relevantes o la flexibilización de las reglas de imputación y de los principios político-criminales de

\footnotetext{
2 Nieto, A. (2012), Bases para un futuro Derecho Penal Internacional del medio ambiente. Anuario de la Facultad de Derecho de la Universidad Autónoma de Madrid, núm. 16, pp. 138, 152 y 153.

${ }^{3} \mathrm{Abel}, \mathrm{M}$. (2002) El blanqueo de dinero en la normativa internacional: especial referencia a los aspectos penales, Santiago: Servicio de publicaciones e intercambio científico, Universidad de Santiago de Compostela, pp. 52 y 53.
} 
garantía, nos oponemos a un aumento de los delitos internacionales y al surgimiento de nuevos tribunales especiales.

No obstante, pese a las discrepancias apuntadas, estimo que se trata de un libro muy recomendable: es didáctico, invita a la reflexión y al debate, y pone el punto de mira en la necesidad de modificar la regulación actual de la responsabilidad de las empresas y de los actos ilícitos que puedan cometer. Ciertamente nos encontramos ante un cambio de paradigma, en el cual los poderes fácticos y económicos son susceptibles de cometer delitos de alcance transnacional o, cuando menos, participar en ellos. Por este motivo es preciso que se implementen las respuestas legislativas adecuadas, bien sea mediante tratados internacionales de naturaleza administrativa, bien sea, en el ámbito de la Unión Europea, mediante reglamentos y directivas detallados, amplios y transversales. Sin embargo, esta respuesta ha de centrarse, inicialmente, en los ámbitos civil, administrativo y laboral, y solo si dichos órdenes fallan, o se muestran insuficientes, ha de acudirse, en virtud del principio de intervención mínima y de ultima ratio, al campo penal. La lúcida reflexión de Ambos sirve para evidenciar que nos encontramos ante un escenario novedoso, discutible y plagado de incertidumbres, por lo que se agradecen estudios como éste: serenos, completos y claros.

\section{Bibliografía}

Abel, M. (2002). El blanqueo de dinero en la normativa internacional: especial referencia a los aspectos penales. Santiago: Servicio de publicaciones e intercambio científico, Universidad de Santiago de Compostela

Ambos, K. (2001). La complicidad a través de acciones cotidianas o externamente neutrales. Revista de Derecho Penal y Criminología, 8, pp. 195-206.

Nieto, A. (2012). Bases para un futuro Derecho Penal Internacional del medio ambiente. Anuario de la Facultad de Derecho de la Universidad Autónoma de Madrid, 16, pp. 137-164. 